\title{
Association of myosin with the connecting cilium of rod photoreceptors
}

\author{
DAVID S. WILLIAMS ${ }^{1, *}$, MARK A. HALLETT ${ }^{1}$ and KENTARO ARIKAWA ${ }^{1,2}$ \\ 'Department of Visual Sciences and Institute for Molecular and Cellular Biology, Indiana University, 800 E. Atwater Ave, Bloomington, \\ Indiana 47405; USA \\ ${ }^{2}$ Department of Biology, Yokohama City University, Yokohama 236, Japan \\ *Author for correspondence
}

\section{Summary}

The cilium of a vertebrate photoreceptor cell connects the phototransductive outer segment of the cell to the inner segment. Previous studies have shown that, within the connecting cilium, there is a small cluster of actin filaments, which play a critical role in the formation of new disk membranes. Here, we have detected a polypeptide in rat rod outer segments that is recognized by myosin heavy chain antibodies and was found to possess other characteristics of conventional non-muscle myosin heavy chain: it comigrates in SDS-PAGE with non-muscle myosin heavy chain; it associates with the cytoskeleton of rod outer segments in an ATP-sensitive manner; and it binds to purified actin filaments in the absence of ATP. Myosin ATPase activity was also detected in isolated rod outer segments. Electron immunomicroscopy revealed that myosin is present in the small actin-containing domain within the connecting cilium at the site of disk membrane morphogenesis. These results pose the possibility that an actin-myosin contractile mechanism functions in the formation of new photoreceptor disk membranes.

Key words: photoreceptor, myosin, cilium, cytoskeleton, membrane turnover.

\section{Introduction}

The outer segment of a vertebrate photoreceptor consists of a stack of phototransductive disk membranes, and is connected to the inner segment by a modified, non-motile cilium (Röhlich, 1975; Fig. 1). The movement of proteins through this connecting cilium is highly regulated. Most membrane proteins appear to be restricted to either the inner or the outer segment. The $\mathrm{Na}^{+}, \mathrm{K}^{+}$-ATPase, for example, is excluded from the outer segment (Schneider and Kraig, 1990). Opsin is transported to the outer segment, and then prevented from moving proximally through the connecting cilium back into the inner segment (Papermaster et al., 1985; Spencer et al., 1988). In contrast, several soluble proteins (arrestin, transducin, and a 33 $\mathrm{kDa}$ phosphoprotein) have been shown to move between the two segments in response to the onset of light or darkness (Brann and Cohen, 1987; Philip et al., 1987; Mangini and Pepperberg, 1988; Whelan and McGinnis, 1988).

The connecting cilium is also the site of the formation of new disk membranes. As part of the turnover of photoreceptor membrane, new disk membrane is added at a rapid rate (Besharse et al., 1977), comparable to the rate of addition of new membrane in growth cones of actively elongating neurites (Pfenninger and MayliePfenninger, 1981; Papermaster et al., 1985). Disk membrane morphogenesis occurs by an evagination of the ciliary plasma membrane, followed by the formation of a disk rim that results in enclosure of the disk by the plasma membrane (Steinberg et al., 1980; Arikawa et al., 1992). At present, very little is known about the molecular mechanisms underlying disk morphogenesis, or the prevention or facilitation of movements of proteins through the connecting cilium, but the cytoskeleton of the cilium is likely to be involved.

The connecting cilium contains a $9+0$ array of microtubules (Röhlich, 1975). Within the cilium, there is a discrete domain of actin filaments (Chaitin et al., 1984; Chaitin and Bok, 1986; Vaughan and Fisher, 1987). The filaments are concentrated in a small region adjacent to the nascent disks, where they project between the microtubule doublets, with their minus ends in the center of the cilium and their plus ends at the plasma membrane. A few filaments also extend along the center of the axoneme, parallel to the microtubules (Arikawa and Williams, 1989; Chaitin and Burnside, 1989; Fig. 1). The actin filaments appear to have a role in the morphogenesis of disk membranes, for their depolymerization by cytochalasin $\mathrm{D}$ results in a perturbation of disk morphogenesis (Williams et al., 1988; Vaughan and Fisher, 1989). The mechanism by which the filaments function in this role remains unknown. Alpha-actinin colocalizes with the actin filaments, suggesting that the filaments may be crosslinked 


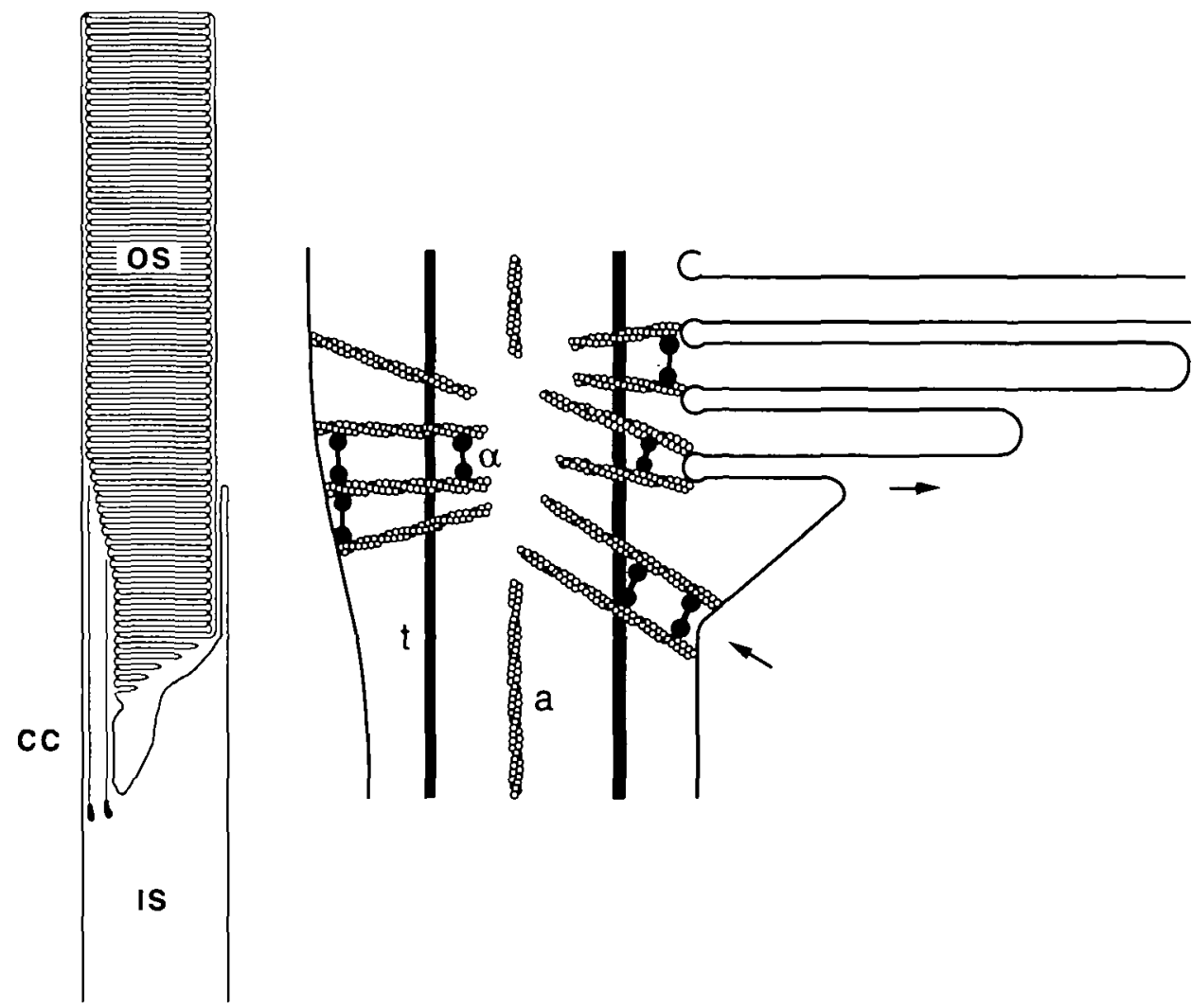

Fig. 1. Diagram of a rod inner (IS) and outer (OS) segment and the connecting cilium (CC). A detailed enlargement of the connecting cilium at the site of disk membrane morphogenesis is shown on the right, with the cytoskeleton organized as described by Arikawa and Williams (1989) Actin filaments (a) have their minus ends near the center of the cilium adjacent to the nascent disks, and their plus ends at the plasma membrane (except for two vertically aligned filaments, which extend beyond the illustrated area). Alpha-actinin $(\alpha)$ is depicted crosslinking actin filaments. The position of microtubules (t), which would be out of the plane of the diagram, is also shown.
(Arikawa and Williams, 1989). However, there has been no clear evidence showing the presence of other actin-associated proteins, including myosin, in the connecting cilium. In order to elucidate how the actin filaments of the photoreceptor-connecting cilium function, a necessary early step is to determine whether a molecular motor protein is associated with them. In this report, we present evidence that conventional myosin (i.e., myosin II) is associated with the actin filaments of the connecting cilium.

\section{Materials and methods}

\section{Animals}

Long Evans rats were bred and maintained under cyclic room lighting (lights-on at 6 a.m., lights-off at 6 p.m.). At $40-60$ days of age, they were decapitated in the mid-morning, and their eyes were quickly enucleated and hemisected. Brains and arterial smooth muscle were removed from some animals.

Adult white leghorn chickens were hooded and decapitated. Their eyes were enucleated and hemisected, and the posterior segment was then dissected so that the pecten was excluded. Gizzard smooth muscle was taken from some animals.

\section{Purification of rod outer segments}

Rod outer segments were purified following the procedure described by Williams et al. (1989). In brief, they were firstly broken off from the inner segment by vortexing retinas in buffer A ( $150 \mathrm{mM} \mathrm{NaCl}, 1 \mathrm{mM}$ EGTA, $1 \mathrm{mM}$ EDTA, $20 \mathrm{mM}$ HEPES, $\mathrm{pH} 7.0$ ). In some cases, $1 \mu \mathrm{M}$ Ep- 475 was included in the buffer (this increased the yield of sealed rod outer segments (Williams et al. 1989), but seemed to have little effect on the relative amount of myosin heavy chain in the rod outer segments). After vortexing, the resulting suspension of rod outer segments was then added to $30 \%$ to $65 \%$ Percoll gradients and centrifuged. Sealed and unsealed rod outer segments were removed from the gradients and separated from the Percoll by centrifugation at $100,000 \mathrm{~g}$ for 1.5 hour. The purified rod outer segments, which aggregate as a loose pellet on top of the solid Percoll pellet, were then incubated in buffered detergent (as below) or solubilized in Laemmli sample buffer with $2 \mathrm{mM}$ EGTA and $0.4 \% 2$-mercaptoethanol for SDS-PAGE and Western blotting.

In order to extract components of the rod outer segments that are soluble in Triton $X-100$, the purified rod outer segments from each lot of 20 retinas were incubated in $3 \mathrm{ml}$ buffer $B\left(100 \mathrm{mM} \mathrm{KCl}, 5 \mathrm{mM} \mathrm{MgCl}_{2}, 1 \mathrm{mM}\right.$ PMSF (phenylmethylsulfonyl fluoride), $24 \mu \mathrm{M}$ leupeptin, $24 \mu \mathrm{M}$ pepstatin, $10 \mu \mathrm{g} / \mathrm{ml}$ phalloidin, $1 \%$ Triton $X-100,20 \mathrm{mM}$ Tris, $\mathrm{pH} 7.5$ ) with mild agitation for 15 minutes on ice, and then centrifuged in a Beckman TLA-100.3 rotor at $541,000 \mathrm{~g}$ for 25 minutes. The supematant and pellet were then separated.

PMSF, leupeptin and pepstatin were purchased from Boehringer Mannheim Biochemicals.

\section{Solubilization by ATP and cosedimentation with actin filaments}

The Triton X-100-insoluble fraction of rod outer segments that were purified from 40 retinas was resuspended in $600 \mu$ of buffer $\mathrm{C}(200 \mathrm{mM} \mathrm{KCl}, 5 \mathrm{mM} \mathrm{MgCl}, 1 \mathrm{mM}$ dithiothreitol (DTT), $0.2 \mathrm{mM}$ PMSF, $24 \mu \mathrm{M}$ leupeptin, $24 \mu \mathrm{M}$ pepstatin, 20

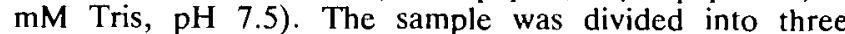
aliquots; buffer $\mathrm{C}$ plus ATP ( $5 \mathrm{mM}$ final concentration) was added to two, and buffer $\mathrm{C}$ alone to the other. After incubation for 20 minutes on ice, during which they were gently vortexed every few minutes, the samples were 
centrifuged in a Beckman TLA-100 rotor for 1 hour at 436,000 $g$. The supernatant of one ATP-treated sample was dialysed to remove the ATP. It was then incubated with purified actin filaments, and centrifuged again at $436,000 \mathrm{~g}$ for 1 hour. Actin filaments were purified from an acetone powder of rabbit back skeletal muscle, following the procedures of Spudich and Watt (1971) and Pardee and Spudich (1982).

All the supernatants were removed, their proteins precipitated with $10 \%$ trichloroacetic acid (TCA), and then pelleted. The pellets and the TCA precipitates were solubilized in Laemmli sample buffer with $2 \mathrm{mM}$ EGTA and $0.4 \% 2$ mercaptoethanol for SDS-PAGE and Western blotting.

\section{Myosin-ATPase assay \\ $\mathrm{K}^{+}$-EDTA ATPase activity of the Triton X-100-insoluble} fraction of rat rod outer segments from 20 rats was measured following the method described by Korn et al. (1982). The pellet was resuspended in $0.5 \mathrm{ml}$ of buffer $\mathrm{D}(10 \mathrm{mM}$ imidazole, $\mathrm{pH} 7.5,0.5 \mathrm{M} \mathrm{KCl}, 2 \mathrm{mM}$ EDTA, $1 \mathrm{mM}$ ATP, 86 $\left.\mu \mathrm{Ci}\left[\gamma_{-}{ }^{32} \mathrm{P}\right] \mathrm{ATP}\right)$ and incubated for 60 minutes at $21^{\circ} \mathrm{C}$ with occasional agitation. A control reaction contained only buffer with no sample. The reaction was stopped by adding $0.5 \mathrm{ml}$ of 2-butanol-benzene and $0.25 \mathrm{ml}$ of $4 \%$ silicotungstic acid in 1.5 $\mathrm{M} \mathrm{H}_{2} \mathrm{SO}_{4}$. After vortexing vigorously for several seconds, 0.3 $\mathrm{ml}$ of $10 \%$ ammonium molybdate was added and the mixture was vortexed again. Phase separation occurred after several minutes. The upper organic phase, containing the phosphomolybdate complex, was then removed and its radioactivity measured in a scintillation counter. The concentration of protein was determined by the bicinchoninic acid (BCA) method (Pierce)

\section{Western blotting and antibodies}

A polyclonal antibody (rabbit $\mathrm{IgG}$ ) against chicken gizzard myosin heavy chain was kindly provided by S.J. Singer's Lab (U.C. San Diego). It was affinity-purified and used at $1 \mu \mathrm{g} / \mathrm{ml}$. A monoclonal antibody (mouse IgG, ascites) against chicken brain myosin heavy chain was kindly provided by $\mathrm{G}$. Conrad and $\mathrm{A}$. Conrad (mAb 23 by their nomenclature). It has been shown to crossreact with non-muscle myosins and chick cardiac myosins, but not with skeletal or smooth muscle myosins (Conrad et al., 1991). Ascites serum was affinitypurified and used at $1 \mu \mathrm{g} / \mathrm{ml}$. Both antibodies have been used previously on studies of adherens junctions in the chicken retina (Williams et al., 1990). A monoclonal antibody against actin was also used; it was made by Lin (1981), and provided by the Developmental Studies Hybridoma Bank (Baltimore).

Proteins were separated in SDS-polyacrylamide slab gels, and either stained with Coomassie blue or electrophoretically transferred to Immobilon (Millipore). Molecular mass markers were obtained from Sigma; they included myosin heavy chain from rabbit skeletal muscle (205 kDa). Electrophoretic transfer was carried out overnight at 40 volts in buffer containing $25 \mathrm{mM}$ Tris, $192 \mathrm{mM}$ glycine, $20 \%$ methanol, $\mathrm{pH} 8.3$.

Western blots were blocked with $5 \%$ milk and $3 \%$ BSA in TBS (Tris-buffered saline), incubated with primary antibody, extensively washed, and then incubated with secondary antibody, and washed again. Secondary antibodies, either goat anti-rabbit IgG or goat anti-mouse IgG, were conjugated to alkaline phosphatase (Promega). Control lanes were incubated with normal rabbit or mouse $\mathrm{IgG}(10 \mu \mathrm{g} / \mathrm{ml})$, instead of the primary antibody.

\section{Electron immunomicroscopy}

Pieces of the posterior segment of each eye were fixed in $0.1 \%$ glutaraldehyde plus $3.0 \%$ paraformaldehyde in $0.1 \mathrm{M}$ phos-

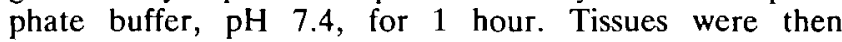
dehydrated in a graded methanol series, infiltrated, and embedded in L.R. White resin. Ultrathin sections were collected on mesh grids covered with Formvar. They were blocked in buffered ( $\mathrm{pH} \mathrm{7.4)} \mathrm{4 \%} \mathrm{BSA,} \mathrm{incubated} \mathrm{with}$ affinity-purified primary antibody (at $10 \mu \mathrm{g} / \mathrm{ml}$ ) for $1-3$ hours, and extensively washed with buffer. They were then incubated with buffered biotinylated goat anti-rabbit IgG or biotinylated goat anti-mouse $\lg G$ for 30 minutes, washed, incubated with buffered streptavidin-gold $(5 \mathrm{~nm})$ for 30 minutes, and washed again. Control sections were incubated with normal rabbit or mouse IgG $(100 \mu \mathrm{g} / \mathrm{ml})$, instead of the primary antibody.

The density of labelling was compared among the four different regions: the outer segment disks, the distal connecting cilium, the proximal connecting cilium, and the inner segment. Student's $t$-test was employed to determine the probability of there being no significant difference between the distal connecting cilium and each of the other regions.

\section{Results}

\section{Western blot analysis}

On Coomassie blue-stained gels of the detergentinsoluble proteins of purified rod outer segments, a polypeptide is evident as a minor band adjacent to the myosin heavy chain relative molecular mass marker (Fig. 2a). Two antibodies against myosin heavy chain were found to recognize a single polypeptide of the same $M_{\mathrm{r}}$ on Western blots of purified rat rod outer segments. Their labelling of rod outer segments was compared with that of whole retina, brain and smooth muscle (Fig. 2b, c). One of the antibodies, a polyclonal, detected at least two closely migrating polypeptides in rat retina, rat brain, and smooth muscle from chicken gizzard and rat artery. In whole chicken retina that had had its pecten removed, so that it contained no vasculature, this antibody reacted with only one polypeptide, which comigrated with the one recognized in rat rod outer segments. The labelled single polypeptide in rod outer segments and chicken retina appeared to comigrate with the fastest migrating labelled polypeptide in whole rat retina and brain (Fig. 2b).

The other antibody, a monoclonal, has been found previously to crossreact with non-muscle and cardiac muscle myosin, but not skeletal or smooth muscle myosin (Conrad et al., 1991). Consistent with this report, we found that the antibody did not recognize any protein in either arterial (not shown) or gizzard smooth muscle (Fig. 2c). In chicken retina, as well as rat brain (not shown) and rat retina, this antibody reacted with a single polypeptide that comigrated with the labelled polypeptide in rat rod outer segments (Fig. 2c). The myosin heavy chain in rod outer segments therefore appears by one-dimensional SDS-PAGE to be similar to the non-muscle form detected in the whole retina and in brain; the other form(s), detected in rat retina and brain by the polyclonal antibody, are most likely from the smooth muscle of the vasculature present in these tissues. 


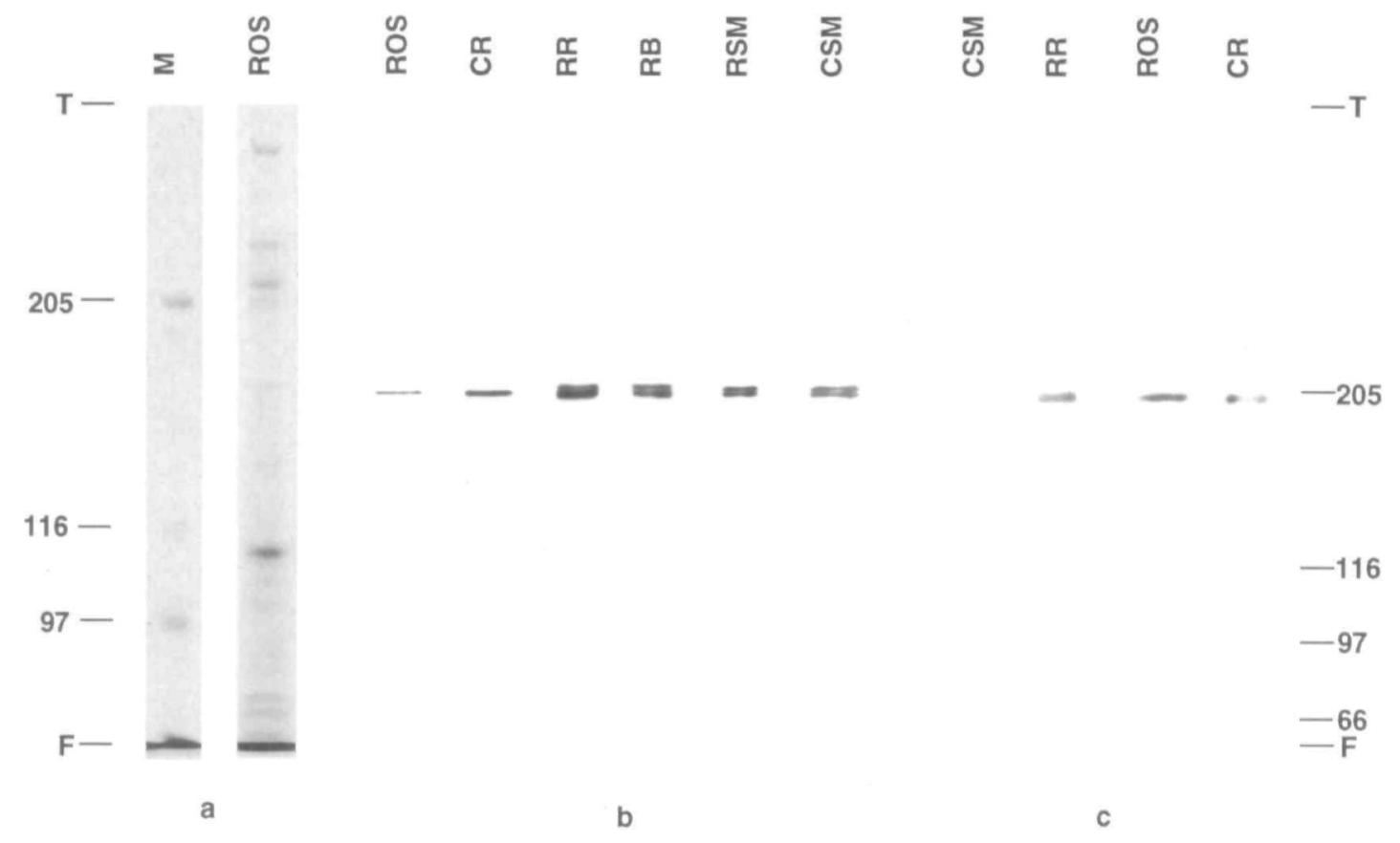

Fig. 2. Purified rat rod outer segments (ROS) and various myosin-containing tissues, immunolabelled with antibodies against myosin heavy chain. (a) Coomassie blue-stained $5 \%$ gel. ROS lane contains $20 \mu$ g of detergent-insoluble protein. Molecular mass (kDa) markers (M) are on the left. (b) Western blot of a $4 \%$ to $6 \%$ gradient gel labelled with a polyclonal antibody shown to recognize both non-muscle and smooth muscle myosins. ROS lane contains $50 \mu \mathrm{g}$ of protein.

(c) Western blot of a $4 \%$ to $6 \%$ gradient gel labelled with a monoclonal antibody that recognizes non-muscle myosin, but not smooth muscle myosin. ROS lane contains $100 \mu \mathrm{g}$ of protein. CR, chicken retina (250 $\mu \mathrm{g}$ protein). RR, rat retina (250 $\mu \mathrm{g}$ protein). $\mathrm{RB}$, rat brain $(250 \mu \mathrm{g}$ protein). RSM, rat arterial smooth muscle (15 $\mu \mathrm{g}$ protein). CSM, chicken gizzard smooth muscle $(3 \mu \mathrm{g}$ protein). Molecular masses $(\mathrm{kDa})$ from standards are indicated on the right for $\mathrm{b}$ and $\mathrm{c}$.

\section{Solubilization by ATP and cosedimentation with actin filaments}

A characteristic of myosins is their ability to bind to actin filaments in an ATP-sensitive manner (Lymm and Taylor, 1971). The polypeptide detected in rod outer segments by the myosin heavy chain antibodies displayed this characteristic. After purified rod outer segments had been incubated with Triton X-100 in the absence of ATP, and then centrifuged, the polypeptide was shown by Western blots to be present in the pellet. Incubation of this pellet with $5 \mathrm{mM}$ ATP for 20 minutes on ice resulted in the solublization of the polypeptide. The amount that was solubilized during this incubation varied from experiment to experiment, but it was

Fig. 3. Western blot of a $5 \%$ to $12 \%$ gradient gel, illustrating the ATP-sensitive binding of myosin to the rod outer segment cytoskeleton and to purified actin filaments. The blot was double-labelled with antibodies against myosin heavy chain (the polyclonal) and actin. $M$, myosin heavy chain. A, actin. The detergent-insoluble fraction of purified rod outer segments was incubated with or without $5 \mathrm{mM}$ ATP, and then centrifuged. Samples of the resulting supernatants $(\mathrm{S})$ and pellets $(\mathrm{P})$ are shown in lanes 1-4. Supernatant from the ATP sample (+ATP/S) was dialysed to remove the ATP, then incubated with purified actin filaments, and centrifuged again. The supernatant and pellet of this last centrifugation are shown in lanes 5 and 6 . Lane 7 (A) contained only the purified actin filaments, and shows that the actin was not contaminated by myosin.
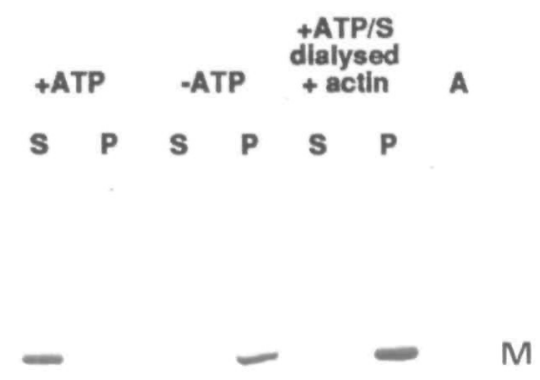
always greater than half; Fig. 3 shows the result of an experiment in which all became soluble. Following the removal of the ATP from the soluble fraction by dialysis, the polypeptide was then found to cosediment with purified actin filaments that were added to the fraction (Fig. 3).

\section{Myosin-ATPase activity}

In order to test for the presence of myosin ATPase activity in rod outer segments, we attempted to measure ATPase activity in presence of $\mathrm{K}^{+}$and EDTA. Under these conditions, the specific activity of the detergent-insoluble fraction of purified rod outer segments was found to be $21.3 \mathrm{nmol} \mathrm{P}_{\mathrm{i}} / \mathrm{min}$ per $\mathrm{mg}$ protein.

\section{Electron immunomicroscopy}

The distribution of myosin in rod outer segments was investigated by immunogold labelling of ultrathin sections of rat retinas. Most labelling with either of the myosin heavy chain antibodies was found in a discrete domain within the connecting cilium of each rod photoreceptor (Figs 4 and 5). This domain appeared to be within the area surrounded by the microtubules, and is adjacent to the nascent disk membranes at the base of the outer segment. Labelling over the outer segment

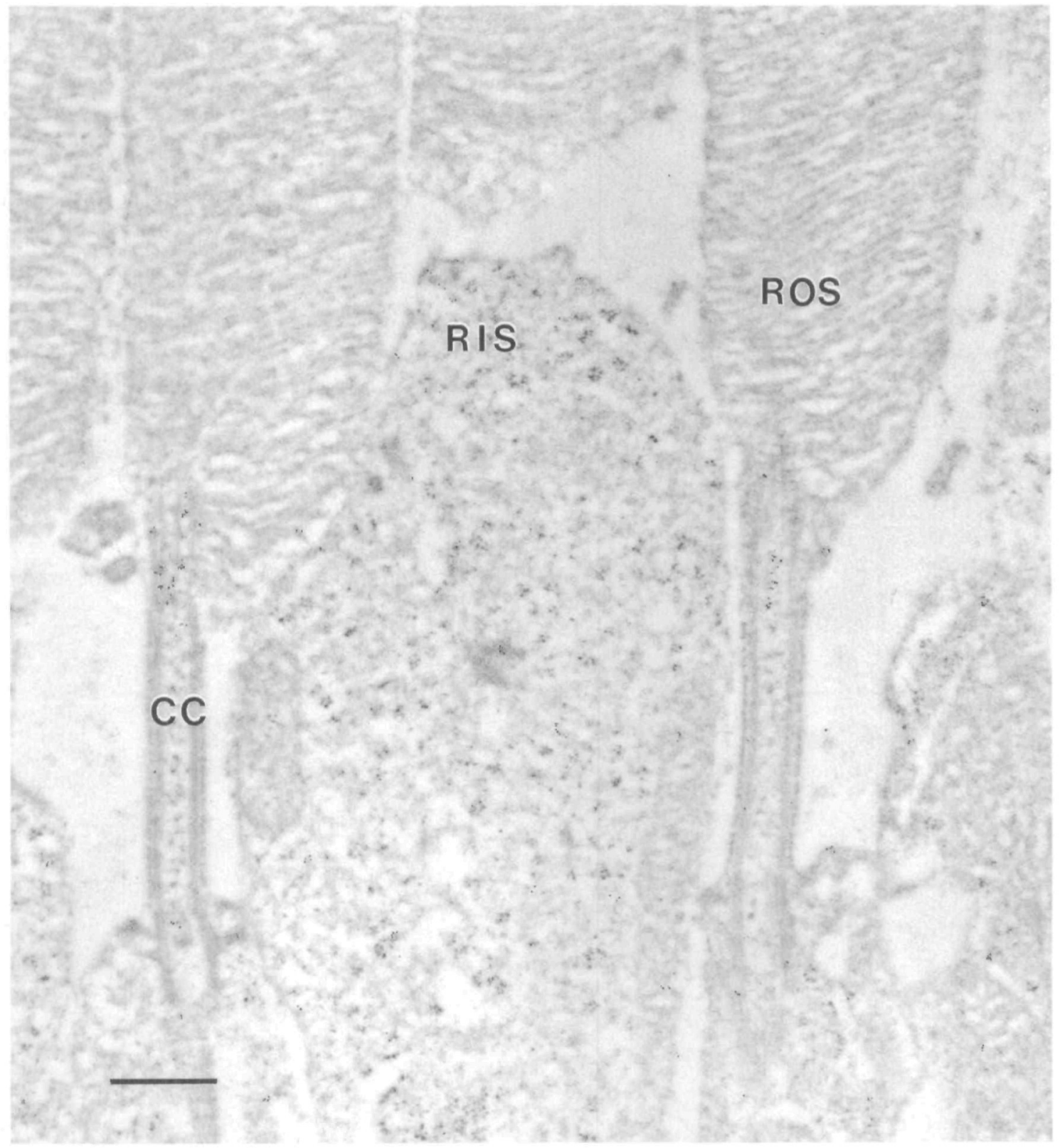

Fig. 4. Indirect immunogold labelling of rat rod photoreceptors with the polyclonal antibody against myosin heavy chain. The section shows connecting cilia (CC) from two rod photoreceptors. ROS, rod outer segment. RIS, rod inner segment. Note that label is present in the connecting cilia adjacent to the bases of the outer segments, but is absent from the disk membranes of the outer segments. Bar, $0.5 \mu \mathrm{m}$. 


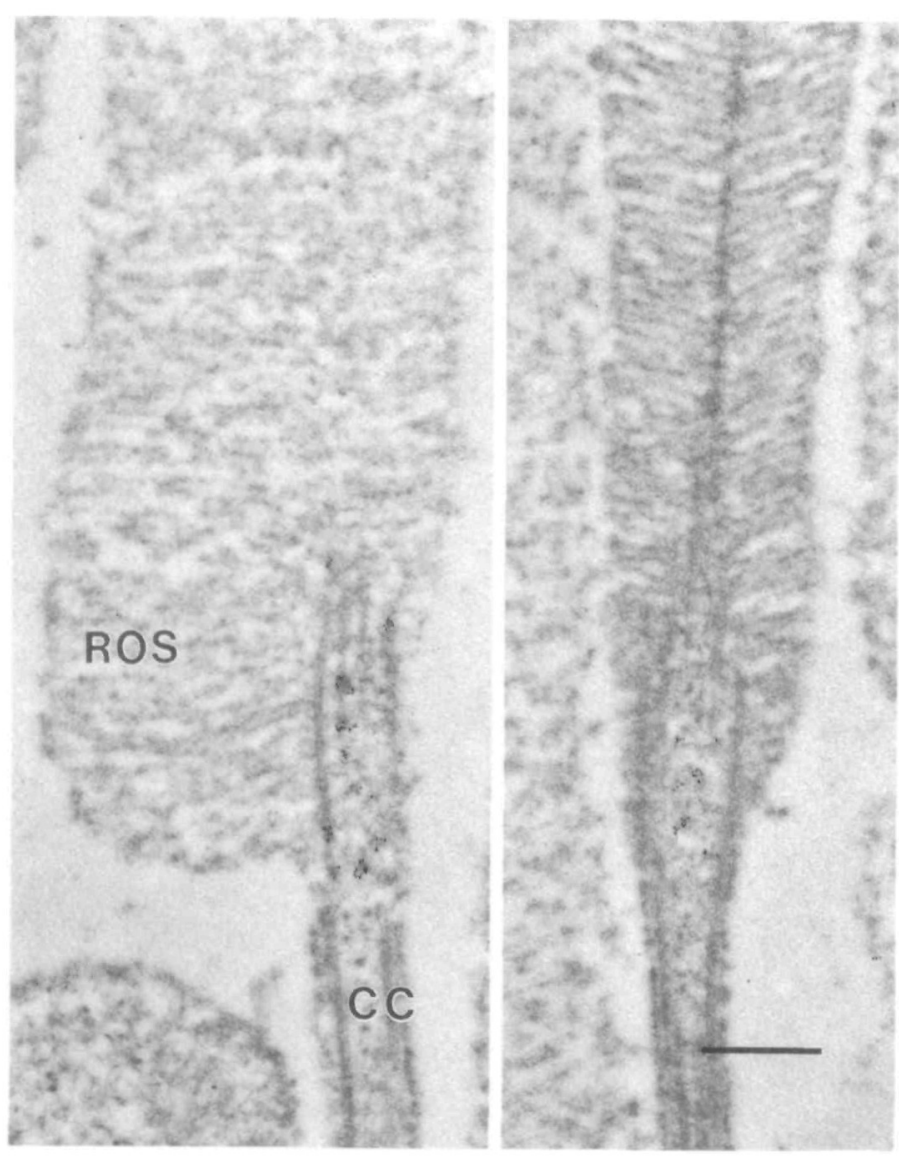

Fig. 5. Indirect immunogold labelling of the connecting cilium (CC) of two different rat rod photoreceptors with the monoclonal antibody (left) and polyclonal antibody (right) against myosin heavy chain. ROS, rod outer segment. Both are at the same magnification; bar, $0.5 \mu \mathrm{m}$.

Table 1. Quantification of immunogold labelling

\begin{tabular}{lc}
\hline Region & $\begin{array}{c}\text { Gold particles } / \mu \mathrm{m}^{2} \\
( \pm \mathrm{s} . \mathrm{e} . \mathrm{m} .)\end{array}$ \\
\hline Disks & $2.3 \pm 0.6$ \\
CC, distal & $110 \pm 26$ \\
CC, proximal & $15 \pm 3$ \\
IS & $13 \pm 6$
\end{tabular}

The distal connecting cilium (CC) is the area adjacent to the outer segment disks. The proximal connecting cilium is between the disks and the inner segment. The inner segment includes the basal bodies of the connecting cilium. Data were obtained from 5 different cells, labelled with the polyclonal antibody against myosin heavy chain. The probability of there being no significant difference between the distal connecting cilium and each of the other regions was less than 0.01 in all cases.

disk membranes was not above that of the background, but some light labelling by the myosin antibodies was detected in the inner segments (Table 1), where bundles of actin filaments have been shown to be present (Drenckhahn and Gröschel-Stewart, 1977; Burnside, 1978; for the first reports).

\section{Discussion}

\section{Different forms of myosin heavy chain in retina}

Our Western blot analyses showed that the rat retina contains more than one form of myosin heavy chain. One of these forms appears to be non-muscle myosin heavy chain, which was the only one detected in purified rod outer segments. Given that the avascular chicken retina (with pecten removed) contained only non-muscle myosin heavy chain, the additional form(s) detected in rat retina and brain by the polyclonal antibody are most likely from the smooth muscle of the vasculature present in these tissues. Smooth muscles have been shown to contain two forms of myosin heavy chain (Rovner et al., 1986). Gröschel-Stewart et al. (1989) were able to resolve three forms of myosin heavy chain in porcine brain, using low percentage polyacrylamide gels and Western blot analysis; they concluded from comparisons with other tissues that the fastest migrating form was non-muscle, and the two slower migrating forms were from smooth muscle. More recently, Murakami et al. (1991) reported that three forms of non-muscle myosin heavy chain were evident in different amounts in distinct regions of rat and bovine brain. It is not known at present whether there is more than one form of non-muscle myosin in the retina.

\section{Myosin in rod outer segments}

The presence of $\mathrm{K}^{+}$-EDTA ATPase activity (a characteristic of myosins) in isolated bovine rod outer segments has been reported in an abstract (Hesketh et al., 1978). However, myosin was not evident in the outer segments of retinas labelled for immunofluorescence microscopy (Drenckhahn and GröschelStewart, 1977; Drenckhahn and Wagner, 1985), and results of electron immunomicroscopic studies have so far been inconclusive (see discussion by Chaitin and Burnside, 1989).

Here, we have detected myosin heavy chain on Western blots of purified rod outer segments, using two different antibodies. It was shown to be solubilized from the rod outer segment cytoskeleton in the presence of ATP, and to bind to purified actin filaments in the absence of ATP, thus manifesting an important characteristic of a myosin. $\mathrm{K}^{+}$-EDTA ATPase activity was also detected in the Triton $\mathrm{X}-100$-insoluble fraction of rat rod outer segments. The specific ATPase activity was 23 times higher than that reported by Hesketh et al. (1978) from bovine rod outer segments that had not been fractionated; the detergent-insoluble fraction is enriched in myosin, which would account for much of the difference.

Results with isolated rod outer segments are clearly compromised by any impurites. The most likely source of contamination comes from the inner segment, parts of which may remain attached to the connecting cilium. Electron immunomicroscopy showed, however, that the concentration of myosin in the inner segment is relatively low (Table 1 ), so that the effect of minor contamination from the inner segment is probably small. It is noteworthy that Percoll gradient isolation of 
rod outer segments provides one of the purest preparations of rod outer segments (Shuster and Farber, 1984; Biernbaum and Bownds 1985; authors' own unpublished observations).

By electron immunomicroscopy we found that, within the rod outer segment, the myosin was restricted to a small domain in the connecting cilium. The connecting cilium has been shown previously to contain actin filaments (Chaitin et al., 1984; Vaughan and Fisher, 1986; Arikawa and Williams, 1989; Chaitin and Burnside, 1989), and alpha-actinin (Arikawa and Williams, 1989). The distribution of myosin within the connecting cilium appears similar to that of actin in that it is concentrated adjacent to the nascent disks. However, nearly all of the myosin labelling was detected within the microtubules, whereas actin filaments extend between the microtubules to the more peripheral parts of the cilium (Arikawa and Williams, 1989; Chaitin and Burnside, 1989).

\section{Comparison with other axonemes}

The presence of actin filaments and myosin within an axoneme is unusual. Although actin antibodies have been shown to label the axonemes of various motile cilia and flagella, NBD-phallacidin (which binds only F-actin) evidently does not (Virtanen et al., 1984; Detmers et al., 1985; Chailley et al., 1986). Myosin has been detected between the basal bodies in oviduct epithelial cells, but appears to be absent from the axonemes (Klotz et al., 1986; Sandoz et al., 1988). It seems likely that the presence of actin filaments and myosin in the connecting cilium of photoreceptor cells is related to a specialized function of this cilium, such as the regulation of protein movements through the cilium, or the formation of new phototransductive disk membranes.

\section{Disk membrane morphogenesis}

A large amount of phototransductive membrane is turned over daily (Besharse et al., 1977), so that the formation of new disk membranes at the connecting cilium represents a major undertaking by photoreceptor cells. Actin filaments have been shown to be necessary for normal disk membrane morphogenesis (Williams et al., 1988; Vaughan and Fisher, 1989). Colocalization of myosin with the actin filaments in the connecting cilium indicates the possibility of an actin-myosin contractile mechanism functioning in disk membrane morphogenesis. Given the organization of the actin filaments in the connecting cilium, with their plus ends at the plasma membrane and their minus ends in the center of the axoneme (Arikawa and Williams, 1989; Chaitin and Burnside, 1989), myosin heads interacting with these filaments would move towards the ciliary plasma membrane. The most likely consequence of this movement would be a mechanical force on the ciliary plasma membrane, resulting in an invagination of the plasma membrane. Perhaps bipolar myosin filaments interact with actin filaments that originate from opposite sides of the cilium and thus have opposite polarity; consistent with such an arrangement, myosin, in comparison to actin, appears to be confined more to the center of the cilium (cf. Figs 4 and 5 with those of Arikawa and Williams, 1989, and Chaitin and Burnside, 1989).

The first stage in the morphogenesis of a photoreceptor disk membrane appears to be a protrusion of the ciliary plasma membrane, followed by a flattening of this protrusion into a disk (Steinberg et al., 1980). The latter could be effected by an invagination of the ciliary plasma membrane at the base of the protrusion (lower arrow in Fig. 1). Supporting this suggestion is the observation that it is the initiation of disk membrane morphogenesis that appears to be dependent on actin filaments; the subsequent outgrowth of a disk, once initiated, can occur in their absence (Williams et al., 1988).

We are grateful to S.J. Singer, G. Conrad and A. Conrad for providing the myosin antibodies, and to the Developmental Studies Hybridoma Bank (supported by NICHD contract N01-HD-6-2915) for the anti-actin. Ep-475 was generously provided by A. D. Blest, from part of a gift he received from the Taisho Pharmaceutical Company, Tokyo. A. Newton helped draw part of Fig. 1, and R. Nickells and C.L. Schlamp made helpful comments on the manuscript. The work was supported by NIH grant EY 07042 to D.W., and NIH Fogarty International fellowship TW 03929 and a Kihara Memorial Yokohama Foundation grant to K.A.

\section{References}

Arikawa, K., Molday, L. L., Molday, R. S. and Williams, D. S. (1992). Localization of peripherin/rds in the disk membranes of cone and rod photoreceptors: relationship to disk membrane morphogenesis and retinal degeneration. J. Cell Biol. 116, 659-667.

Arikawa, K. and Williams, D. S. (1989). Organization of actin filaments and immunocolocalization of alpha-actinin in the connecting cilium of rat photoreceptors. J. Comp. Neurol. 288, 640 646.

Besharse, J. C., Hollyfield, J. G. and Rayborn, M. E. (1977). Turnover of rod photoreceptor outer segments. II. Membrane addition and loss in relationship to light. J. Cell Biol. 75, 507-527.

Biernbaum, M. S. and Bownds, M. D. (1985). Frog rod outer segments with attached inner segment ellipsoids as an in vitro model for photoreceptors of the retina. J. Gen. Physiol. 85, 83-105.

Brann, M. R. and Cohen, L. V. (1987). Diurnal expression of transducin mRNA and translocation of transducin in rods of rat retina. Science 235, 585-587.

Burnside, B. (1978). Thin (actin) and thick (myosinlike) filaments in cone contraction in the teleost retina. J. Cell Biol. 78, 227-246.

Chailley, B., Bork, K., Gounon, P. and Sandoz, D. (1986) Immunological detection of actin in isolated ciliar from quail oviduct. Biol. Cell. 58, 43-52.

Chaitin, M. H. and Bok, D. (1986). Immunoferritin localization of actin in retinal photoreceptors. Invest. Ophthalmol. Vis. Sci. 27, 1764-1767

Chaitin, M. H. and Burnside, B. (1989). Actin filament polarity at the site of rod outer segment disk morphogenesis. Invest. Ophthalmol. Vis. Sci. 30, 2461-2469.

Chaitin, M. H., Schneider, B. G., Hall, M. O. and Papermaster, D. S. (1984). Actin in the photoreceptor connecting cilium: Immunocytochemical localization to the site of outer segment disk formation. J. Cell Biol. 99, 239-247.

Conrad, A. H., Clark, W. A. and Conrad, G. W. (1991). Subcellular compartmentalization of myosin isoforms in embryonic chick heart ventricle myocytes during cytokinesis. Cell Motil. Cytoskel. 19, 189 206 
Detmers, P. A., Carboni, J. M. and Condeelis, J. (1985). Localization of actin in Chlamydomonas using antiactin and NBD-Phallacidin. Cell Motil. 5, 415-430.

Drenckhahn, D. and Gröschel-Stewart, U. (1977). Localization of myosin and actin in ocular nonmuscle cells. Cell Tiss. Res. 181, 493 503.

Drenckhahn, D. and Wagner, H. J. (1985). Relation of retinomotor responses and contractile proteins in vertebrate retinas. Eur. J. Cell Biol. 37, 156-168.

Gröschel-Stewart, U., Magel, E., Elke, P. and Neidlinger, A. C. (1989). Pig brain homogenates contain smooth muscle myosin and cytoplasmic myosin isoforms. Cell Tiss. Res. 257, 137-139.

Hesketh, J., Virmaux, N. and Aunis, D. (1978). Evidence for myosin associated with bovine photorecptor cell outer segments. Biochem. Soc. Trans. 6, 1271-1272.

Klotz, C., Bordes, N., Laine, M. C., Sandoz, D. and Bornens, M. (1986). Myosin at the apical pole of ciliated epithelial cells as revealed by a monoclonal antibody. J. Cell Biol. 103, 613-619.

Korn, E. D., Collins, J. H. and Maruta, H. (1982). Myosins from Acanthamoeba castellanii. Methods Enzymol. 85, 357-363.

Lin, J. J. C. (1981). Monoclonal antibodies against myofibrillar components of rat skeletal muscle decorate the intermediate filaments of cultured cells. Proc. Nat. Acad. Sci. USA 78, 23352339.

Lymm, R. W. and Taylor, E. W. (1971). Mechanism of adenosine triphosphate hydrolysis by acto-myosin. Biochemistry 10, 4617 4624.

Mangini, N. J. and Pepperberg, D. R. (1988). Immunolocalization of $48 \mathrm{~K}$ in rod photoreceptors. Invest. Ophthalmol. Vis. Sci. 29, 12211234.

Murakami, N., Mehta, P. and Elzinga, M. (1991). Studies on the distribution of cellular myosin with anitbodies to isoform-specific synthetic peptides. FEBS Lett. 278, 23-25.

Papermaster, D. S., Schneider, B. G. and Besharse, J. C. (1985) Vesicular transport of newly synthesized opsin from the Golgi apparatus toward the rod outer segment. Invest. Ophthalmol. Vis. Sci. 26, 1386-1404.

Pardee, J. D. and Spudich, J. A. (1982). Purification of muscle actin. In Methods in Cell Biology, vol. 24, The Cytoskeleton, Part A (ed L. Wilson), pp. 271-289. Academic Press, Orlando.

Pfenninger, K. H. and Maylie-Pfenninger, M. F. (1981). Lectin labeling of sprouting neurons. 11. Relative movement and appearance of glycoconjugates during plasmalemmal expansion. $J$. Cell Biol. 89, 547-557.

Philip, N. J., Chang, W. and Long, K. (1987). Light-stimulated protein movement in rod photoreceptor cells of the rat retina. FEBS Lett. 225, 127-132.

Röhlich, P. (1975). The sensory cilium of retinal rods is analogous to the transitional zone of motile cilia. Cell Tiss. Res. 161, 421430.

Rovner, A. S., Murphy, R. A. and Owens, G. K. (1986). Expression of smooth muscle and nonmuscle myosin heavy chains in cultured vascular smooth muscle cells. J. Biol. Chem. 261, 14740-14745.

Sandoz, D., Chailley, B., Bokvieux-Ulrich, E., Lemuleois, M., Laine, M. and Bautista-Harris, G. (1988). Organization and functions of cytoskeleton in metazoan ciliated cells. Biol. Cell. 63, 183-193.

Schneider, B. G. and Kraig, E. (1990). $\mathrm{Na}^{+}, \mathrm{K}^{+}$-ATPase of the photoreceptor: selective expression of $\mathrm{a}_{3}$ and $\mathrm{b}_{2}$ isoforms. Exp. Eye Res. 51, 553-564.

Shuster, T. A. and Farber, D. B. (1984). Phosphorylation in sealed rod outer segments: effects of cyclic nucleotides. Biochemistry 23 , 515-521.

Spencer, M., Detwiler, P. B. and Bunt-Milam, A. H. (1988) Distribution of membrane proteins in mechanically dissociated retinal rods. Invest. Ophthalmol. Vis. Sci. 29, 1012-1020.

Spudich, J. A. and Watt, S. (1971). The regulation of rabbit skeletal muscle contraction. J. Biol. Chem. 246, 4866-4871.

Steinberg, R. H., Fisher, S. K. and Anderson, D. H. (1980). Disc morphogenesis in vertebrate photoreceptors. J. Comp. Neurol. $190,501-518$

Vaughan, D. K. and Fisher, S. K. (1987). The distribution of F-actin in cells isolated from vertebrate retinas. Exp. Eye Res. 44, 393-406.

Vaughan, D. K. and Fisher, S. K. (1989). The effects of cytochalasin $\mathrm{D}$ in the rabbit retina. Invest. Ophthalmol. Vis. Sci. 30, 339-342.

Virtanen, I., Bradley, R. A., Paasivuo, R. and Lehto, V.-P. (1984). Distinct cytoskeletal domains revealed in sperm cells. J. Cell Biol. 99, 1083-1091.

Whelan, J. P. and McGinnis, J. F. (1988). Light-dependent subcellular movement of photoreceptor proteins. J. Neurosci. Res. 20, 263-270.

Williams, D. S., Arikawa, K. and Paallysaho, T. (1990). Cytoskeletal components of the adherens junctions between the photoreceptors and the supportive muller cells. J. Comp. Neurol. 295, 155-164.

Whlliams, D. S., Linberg, K. A., Vaughan, D. K., Fariss, R. N. and Fisher, S. K. (1988). Disruption of microfilament organization and deregulation of disk membrane morphogenesis by cytochalasin $\mathrm{D}$ in rod and cone photoreceptors. J. Comp. Neurol. 272, 161-176.

Williams, D. S., Shuster, T. A., Moldrawski, M. R., Blest, A. D. and Farber, D. B. (1989). Isolation of rod outer segments on percoll gradients: effect of specific protease inhibition. Exp. Eye Res. 49, 439-444.

(Received 22 January 1992 - Accepted, in revised form, 